\title{
Incidence of Gastrointestinal Cancers in Iran: A Systematic Review
}

\author{
Kourosh Zarea, ${ }^{1}$ Samira Beiranvand, ${ }^{1,}$ Saeed Ghanbari, ${ }^{2}$ and Hanna Tuvesson ${ }^{3}$ \\ ${ }^{1}$ Nursing Care Research Center in Chronic Diseases, Ahvaz Jundishapur University of Medical Sciences, Ahvaz, IR Iran \\ ${ }^{2}$ Department of Biostatistics, School of Medicine, Shiraz University of Medical Sciences, Shiraz, IR Iran \\ ${ }^{3}$ Blekinge Institute of Technology, Department of Health, Karlskrona, Sweden \\ "Corresponding author: Samira Beiranvand, Nursing Care Research Center in Chronic Diseases, Ahvaz Jundishapur University of Medical Sciences, Ahvaz, IR Iran. Tel/Fax: \\ +98-6113738333, E-mail: beiranvandsamira@yahoo.com
}

Received 2016 February 19; Revised 2016 May 27; Accepted 2016 June 20.

\begin{abstract}
Context: In service planning, indicators such as incidence can aid the development of strategies for service provision. The current systematic review was carried out to provide a general viewpoint on incidence, geographical and age distribution of gastrointestinal (GI) cancers in Iran.

Evidence Acquisition: A detailed Science Direct, PubMed, Scopus, Google Scholar, Iran Medex, Magiran and SID (scientific information databases) search was made from 2005 to 2015 . The basic inclusion criteria were all relevant studies focused on GI cancers incidence and epidemiologic data from Iran.

Results: Overall incidence of cancer was 19.4 and 17.2 per 100000 in males and females, respectively. The three most common GI cancers in males were: esophagus, stomach and colorectal and in females: colorectal, stomach and esophagus. The highest incidence rate was observed in Golestan province and in the age group over 65 years.

Conclusions: According to increasing incidence rate of GI cancers in Iran, development, establishment and implement of comprehensive national cancer control program should be the first priorities for health policy makers.
\end{abstract}

Keywords: Cancer, Incidence of Cancer, Epidemiology of Cancer, Cancer Occurrence, Cancer in Iran

\section{Context}

Gastrointestinal (GI) cancers are reported as the most common fatal cancer in different regions of Iran (1,2). Also previous studies in Iran reported the incidence rates of gastrointestinal cancers were high (it is one of the known areas with a high incidence of GI cancers) $(3,4)$. The related studies demonstrated that GI cancers account for $57 \%$ of all cancers in the study region and the upper GI tract malignancies contribute to $47.8 \%$ of all cancers in Golestan province, Iran, in which esophageal and gastric cancers constitute $31.2 \%$ and $16.6 \%$ of all cancers, respectively (5). Given to decrease the burden of such diseases, first, the number of patients affected should be found out. The impact of these diseases on the health, budget and resources of the society should be determined. On the other hand, the statistics should be updated periodically to identify the trends in incidence, prevalence and mortality of different diseases with important implications for health policy planning (6). Besides, the current guidelines recommend to consider the screening age of 50 for average-risk persons and an earlier age for persons at higher risk (7, 8 ), but designing and implementing screening programs in each country largely depends on basic epidemiological information including evaluating the magnitude of the problem, identifying average and high risk populations, determining the most common site of tumor and distribution of age at diagnosis (9). Variations concerning the incidence of different cancers in Iran are a subject of inter- est and necessitate reliable cancer registries to supply data about the incidence, burden and changes in mortality and morbidity over years (4). Therefore, the current information concerning the incidence of cancer in Iran is scant and incomplete.

\subsection{Objectives}

The current systematic review and meta-analysis aimed to estimate the incidence of gastrointestinal cancers in Iran and explain incidental differences that may help to design and establish early cancer detection programs and investigate population risk factors.

\section{Evidence Acquisition}

In the current systematic review study, a comprehensive computer-assisted publication search was conducted using the databases of Science Direct, PubMed, Google Scholar and Scopus, and through Persian texts in Iran Medex (indexing articles published in Iran biomedical journals), Magiran (Iranian magazines database), and SID (scientific information database). In addition, manual reviews of the reference lists of studies identified during electronic searches were also undertaken and electronic links to additional related materials were reviewed. The literature search was also supplemented by a manual review of 'grey literature'; conference presentations, project reports, government reports and health-care organizational 
agency reports. Searches included the following keywords: cancer, incidence, epidemiology, occurrence and cancer in Iran. The search results were restricted to contain these keywords in the titles of the articles. The keywords were entered singly and combined in the process of the search. Duplicate publications were removed. After removal of duplicate studies, each unique title and abstract was independently reviewed by two researchers to determine whether it fit pre-determined inclusion criteria and relevance to the aim of the review. All studies that met title and abstract criteria were selected for full text review. The inclusion criteria were: 1) Studies that reported results concerning cancer incidence in Iran, 2) Studies published from 2005 to 2015 and 3) Studies published in English and Persian languages. The initial search strategies yielded 18279 references for all mentioned databases. After removal of duplicates, a total of 8628 studies were identified; cancer (6355 articles), epidemiology of cancer (85), incidence of cancer (454), cancer occurrence (85), and cancer in Iran (278). Also, 902 abstracts were reviewed and 80 studies appeared to be relevant to the review. After further screening in regard to the inclusion criteria only 30 potential studies were identified. Of these, seven studies were excluded since the number of patients could not be calculated and another 13 repeated studies were excluded. The remaining 13 studies $(1,4,5,10$ 19) were deemed eligible and selected for analysis and inclusion in the review.

\subsection{Data Extraction}

Where available, the following data were extracted from each of the 13 included studies: the first author (e.g. Semnani et al. (5), study location (the relevant province), year of publication, number of patients in the study, proportion of patients at baseline who were male, female and the mean age of patients (Table 1). Information was also extracted concerning the number of cancer cases and types of cancers in relation to province, gender and age.

\subsection{Analysis}

In the current meta-analysis, the incidence of cancer was calculated by dividing the number of cancers incidence by the total number of person-year of observation, for each of the included studies. Exact methods, based on the Poisson distribution, were used to calculate 95\% confidence intervals for the rate of each type of cancer for presentation in forest plots. Meta-analysis models were applied by the log incidence rates of each type of cancer standard errors. Heterogeneity between studies was investigated by the $\chi^{2}$ test and the $\mathrm{I}^{2}$ test. The $\mathrm{I}^{2}$ test measures the proportion of variation in the study estimates due to heterogeneity. A random-effects (20) model was used to calcu- late a pooled estimate of the incidence rate from the combined studies. All statistical analyses were performed by Stata software version 9.2 (Stata Corporation, college station, Texas) (Figures 1 and 2).

\section{Results}

The current review included recent research literature concerning the epidemiology and incidence of GI cancers. A total of 13 articles were included for integrative review (1, $4,5,10-19)$. Only Iranian researches were reviewed to survey the incidence of cancer. Of the 13 studies included in the review, six investigated the incidence of various types of cancers; seven examined the incidence of digestive system cancers (e.g. esophageal, colorectal, pancreas and biliary ducts cancers). Locations of the 13 studies included in the present review were Golestan, East Azerbaijan, Ardebil, Kerman, Kurdistan, Fars, Guilan, Tehran and Mazandaran provinces. Three of the included studies investigated incidence of cancers throughout the country. The age categories of the included studies were similar and comprised the following age groups; 0 - 14, 15 - 24, 25 - 34, 35 - 44, 45 - 54, 55 - 64 and $\geq 65$ years. All 13 studies reported incidence of each type of cancer in connection to both genders and all age categories. All included studies provided data that could be used to analyze GI cancers incidence in Iran. However, there was evidence of considerable heterogeneity in this pooled analysis. The results of measured pooled incidence for each cancer are presented in Table 2. This systematic review showed that overall incidence of cancer was 19.4 and 17.2 per 100000 in males and females, respectively (95\% confidence interval (CI): 19.2, 19.6 - 17.05, 17.4, respectively). Based on the study results, the three most common GI cancers in males (by ASR) were: esophagus ( 4.7 per 100,000), stomach (3.7 per 100,000) and colorectal (2.9 per 100,000). In females the three most common GI cancers were: colorectal (4.3 per 100,000), stomach (2.5 per 100,000) and esophagus (2.03 per 100,000).

Also results of the systematic review showed that geographical distribution of types of GI cancers in Iran provinces (by ASR) were Golestan (173.7 per 100 000), East Azerbaijan (69.1 per 100 000), Kerman (31.4 per 100 000) and Guilan (19.3 per 100 000), respectively (Table 3).

\section{Discussion}

This systematic review showed that overall incidence of gastrointestinal cancers in Iran was higher in males than females. It was similar to the previous research of GI cancers in Iran, where the gender ratio of cancer in males was higher than that of females $(21,22)$. One reason for this 
Table 1. Studies Included in the Systematic Review and Meta-Analysis on the Incidence of Gastrointestinal Cancers in Iran

\begin{tabular}{|c|c|c|c|c|c|c|}
\hline First Author & Province & Year & No. of Cases & Male (\%) & Female (\%) & Mean Age, $y$ \\
\hline Semnani et al. (5) & Golestan & 2006 & 5143 & 59.6 & 40.4 & 60 \\
\hline $\begin{array}{l}\text { Mehrabani et al. } \\
\text { (10) }\end{array}$ & Fars & 2008 & 3115 & 47.9 & 52.1 & NA \\
\hline Somi et al. (1) & East Azerbaijan & 2006 & 5417 & 61.7 & 37.6 & 59.45 \\
\hline Somi et al. (4) & East Azerbaijan & 2008 & 4922 & 56.8 & 43 & 60.2 \\
\hline Mirzaei et al. (11) & All provinces & 2015 & 25952 & 54 & 46 & NA \\
\hline Mousavi et al. (12) & All provinces & 2009 & 55855 & 43.8 & 56.2 & NA \\
\hline Safaee et al. (13) & All provinces & 2012 & 19617 & 44 & 56 & 58.9 \\
\hline $\begin{array}{l}\text { Zeinalzadeh et al. } \\
\text { (14) }\end{array}$ & Ardebil & 2015 & 3832 & 53.5 & 46.5 & 58.1 \\
\hline \multirow{4}{*}{ Taefi et al. (15) } & Guilan & \multirow{4}{*}{2008} & \multirow{4}{*}{626} & \multirow{4}{*}{43.2} & \multirow{4}{*}{56.8} & \multirow{4}{*}{63} \\
\hline & Golestan & & & & & \\
\hline & Ardebil & & & & & \\
\hline & Kerman & & & & & \\
\hline \multirow{3}{*}{$\begin{array}{l}\text { Esmaeelnasab et } \\
\text { al. (16) }\end{array}$} & Kurdistan & \multirow{3}{*}{2006} & \multirow{3}{*}{1299} & \multirow{3}{*}{61.7} & \multirow{3}{*}{38.3} & \multirow{3}{*}{ NA } \\
\hline & Ardebil & & & & & \\
\hline & Guilan & & & & & \\
\hline \multirow{3}{*}{ Ansari et al. (17) } & Mazandaran & \multirow{3}{*}{2006} & \multirow{3}{*}{2055} & \multirow{3}{*}{54.9} & \multirow{3}{*}{44} & \multirow{3}{*}{ NA } \\
\hline & Golestan & & & & & \\
\hline & Kerman & & & & & \\
\hline Zahedi et al. (18) & Kerman & 2005 & 1303 & 59.1 & 40.8 & 51.5 \\
\hline $\begin{array}{l}\text { Khabazkhub et al. } \\
\text { (19) }\end{array}$ & Tehran & 2009 & 34269 & 54 & 46 & NA \\
\hline
\end{tabular}

Table 2. Pooled ES, 95\% Confidence Interval and I-Squared of the Incidence of Gastrointestinal Cancers in Iran in the Systematic Review

\begin{tabular}{|c|c|c|c|c|c|c|c|c|}
\hline \multirow[t]{2}{*}{ Type of Cancer } & \multicolumn{2}{|c|}{ I-V Pooled ES } & \multicolumn{2}{|c|}{ 95\% Confidence Interval } & \multicolumn{2}{|c|}{ \% Weight } & \multicolumn{2}{|c|}{ I-Squared (\%) } \\
\hline & Male & Female & Male & Female & Male & Female & Male & Female \\
\hline Esophagus & 4.723 & 2.035 & $4.580-4.867$ & $1.941-2.129$ & 30.11 & 69.89 & 99.7 & 99.5 \\
\hline Stomach & 3.745 & 2.527 & $3.617-3.872$ & $2.422-2.632$ & 40.29 & 59.71 & 99.7 & 99.1 \\
\hline Colorectal & 2.930 & 4.314 & $2.811-3.050$ & $4.215-4.414$ & 86.63 & 13.37 & 99.9 & 99.8 \\
\hline Pancreas & 1.027 & 0.194 & $0.961-1.094$ & $0.165-0.223$ & 15.89 & 84.11 & 98.5 & 95.6 \\
\hline Oral cavity & 0.743 & 2.020 & 0.706-0.779 & $1.920-2.119$ & 88.24 & 11.76 & 99.8 & 99.8 \\
\hline Biliary ducts & 0.438 & 0.339 & $0.317-0.559$ & $0.232-0.445$ & 43.62 & 56.38 & 65.2 & 0 \\
\hline Liver & 0.343 & 0.162 & $0.303-0.383$ & $0.134-0.189$ & 32.03 & 67.97 & 97.5 & 97 \\
\hline Gallbladder & 0.256 & 0.394 & $0.223-0.288$ & $0.354-0.434$ & 60.65 & 39.35 & 89.6 & 97.1 \\
\hline Small intestine & 0.225 & 0.222 & $0.159-0.291$ & $0.129-0.314$ & 100 & 50.77 & 95.8 & 93.8 \\
\hline
\end{tabular}

result could be appointed to risk behaviors such as smoking, alcohol consumption and drug abuse, which are more common in males in Iran; but then again Iranian females are exposed to other risk factors for cancer such as inactivity (13).

Based on the study results, the three most common GI cancers in males were esophagus, stomach and colorectal, respectively. In this regard, Semnani et al., based on the national cancer registry reports, noticed that the most common GI cancers among Iranian males were esophagus, stomach and colorectal cancer (5). In contrast, Somi et al. reported that gastric cancer was significantly more com- mon among males (1). On the other hand, in the current systematic review, the most common GI cancers in females were colorectal, stomach and esophagus, respectively. Zahedi et al. demonstrated that colorectal cancer was at the top of all GI cancers in females (18), which is consistent with the current review results.

Since the differences observed in the incidence rates between regions can play an important role in decoding risk factors; therefore, the second outcome of the current systematic review was the geographical distribution of GI cancers in Iran (23). Based on the results, it was found that the highest GI cancers incidence such as esophagus 


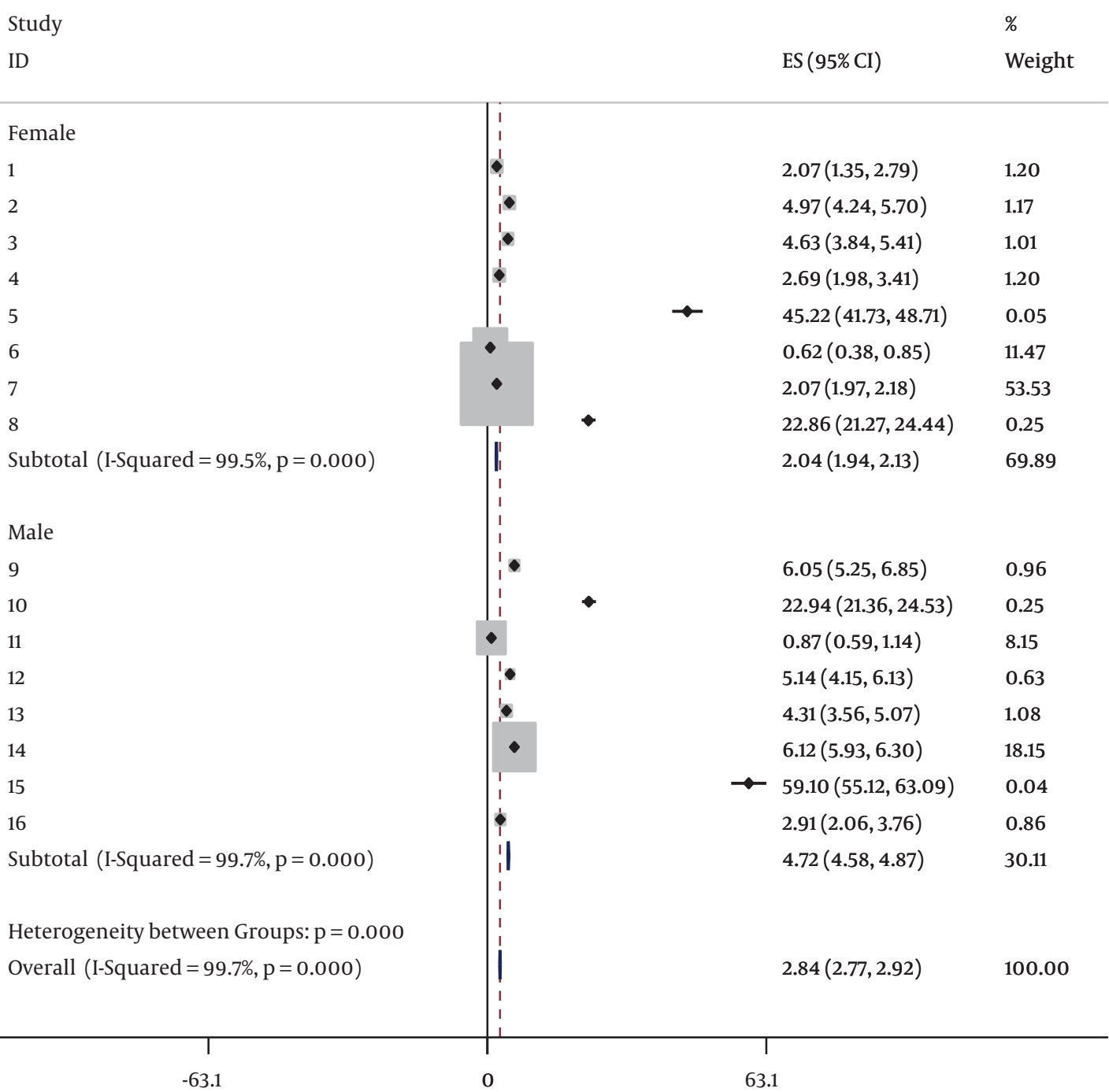

Figure 1. Forrest Plot of I-V Pooled Meta-Analysis of the Incidence of Esophagus Cancer in Males and Females in Iran

and gastric cancer in Iran related to Golestan province. Golestan province in North-Eastern Iran is one of the highest risk areas of the world (24). The explanation for the higher frequency of the said cancers is not clear but many risk factors are associated with the development of cancers, and the pathogenesis is most likely multifactorial including a combination of genetic and environmental factors (20). Many environmental factors including smoking, high salt intake and a diet with an insufficient level of antioxidants are involved in the pathogenesis of gastric cancer (3). Earlier studies in Golestan suggested that low intake of fresh fruits and vegetables, low socioeconomic status and opium consumption are associated with a higher risk of esophageal cancer. In addition, studies pointed to the possible role of drinking very hot tea. In addition, GI cancers are multi-factorial diseases and develop as a result of continuous cell damage caused by life-long exposure to different carcinogens. Smoking, high intake of some traditional salt-preserved foods and salt per se, frequent consumption of red meat, frequently observed among the patients with cancer in the said provinces of Iran were mentioned in previous studies (25).

On the other hand, the highest incidence rate was observed in the age group over 65 years. According to the increasing incidence of GI cancers after the age of 50 , it seems that onset of screening at age 50 would be appropriate. If 


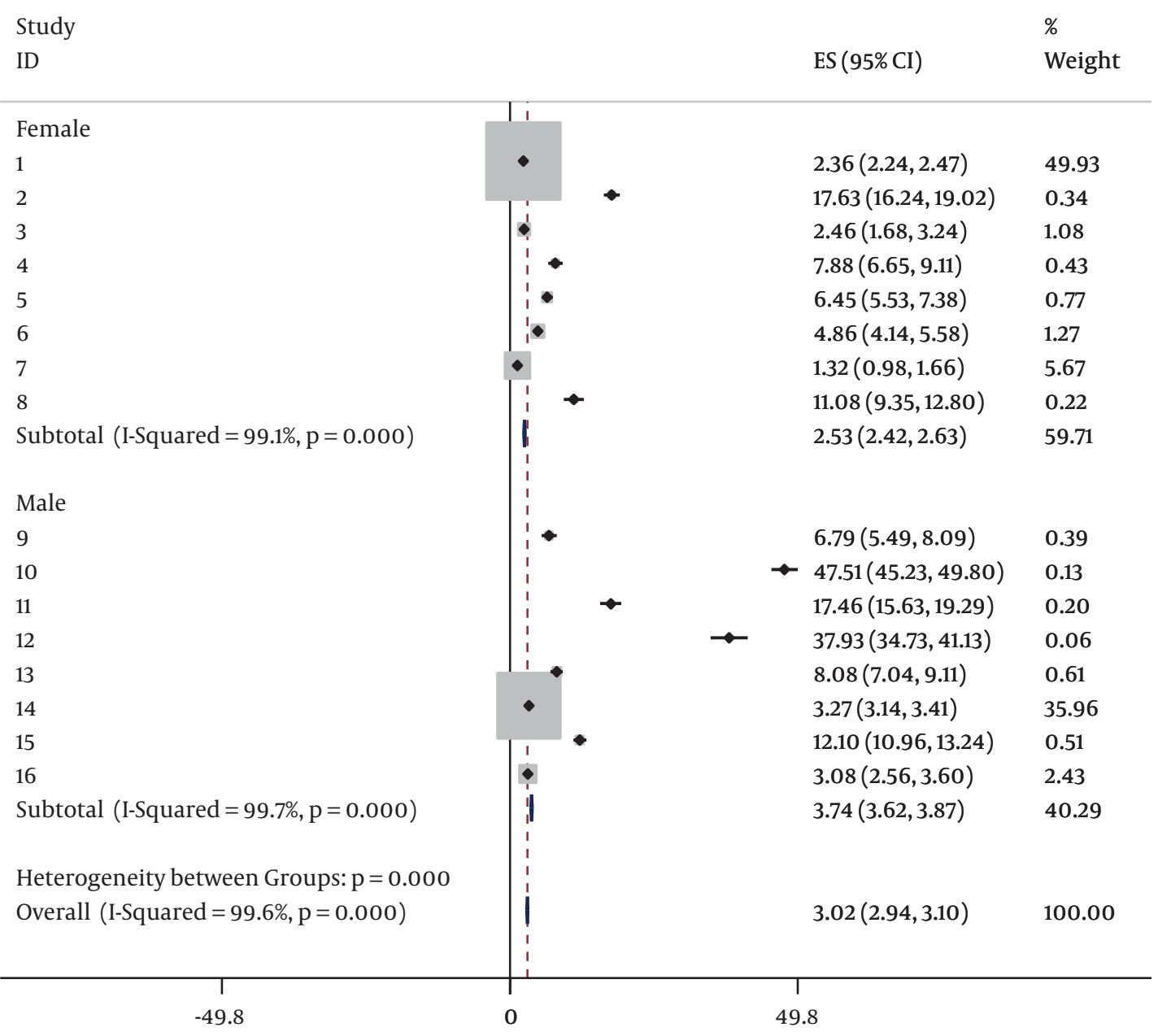

Figure 2. Forrest Plot of I-V Pooled Meta-Analysis of the Incidence of Stomach Cancer in Males and Females in Iran

GI cancers screening is to be considered, all the discussed characteristics and differences such as age, gender and geographical distribution should be taken into account. Unfortunately, in Iran, cancer screening is not done in general and patients are considered individually. Although it is strongly advocated that screening test should be done after specific ages, especially in patients who are at risk, or in those who have positive family history; simply because of high illiteracy level in Iranian population in the countryside, they are not completely aware of the importance of screening. They are not checked routinely and sometimes they are diagnosed only at the end stage. In metropolitan areas, people have more access to specialized centers and may be screened by their own physicians; but it is not always the case.

In the interpretation of the study findings, some lim- itations should be considered. First, the analyses were based on data on previous studies in the field of gastrointestinal cancers incidence by age, gender and geographical region. Second, the study used a retrospective method and the data were limited to what had been captured by the registries. Also, there was no access to details of the information such as the number of gastrointestinal cancers incidence and the total number of person-year of observation to calculate the incidence rate in some studies. In results, authors had to remove the mentioned studies.

\section{References}

1. Hossein Somi M, Mirinezhad K, Farhang S, Jazayeri E, Sani A, SeifFarshadi M, et al. Gastrointestinal cancer occurrence in East Azarbaijan: a five year study from North Western Iran. Asian Pac J Cancer Prev. 2006;7(2):309-12. [PubMed: 16839228]. 
Table 3. Geographical Distribution of Gastrointestinal Cancers Incidence in Iran in the Systematic Review

\begin{tabular}{|c|c|c|c|c|c|}
\hline Type of Cancer & Province & I-V Pooled ES & 95\% Confidence Interval & \% Weight & I-Squared (\%) \\
\hline \multirow{2}{*}{ Biliary ducts } & Guilan & 0.134 & $0.082-0.187$ & 3.74 & 0 \\
\hline & Golestan & 0.014 & $-0.003-0.031$ & 35.65 & 0 \\
\hline \multirow{2}{*}{ Colorectal } & Golestan & 11.883 & $10.618-13.148$ & 0.07 & 97.3 \\
\hline & Kerman & 9.546 & $8.590-10.503$ & 0.12 & 100 \\
\hline \multirow{2}{*}{ Esophagus } & East Azerbaijan & 8.734 & $8.248-9.220$ & 2.62 & 99.6 \\
\hline & Golestan & 51.240 & $48.614-53.866$ & 0.09 & 96.2 \\
\hline \multirow{2}{*}{ Gallbladder } & East Azerbaijan & 0.613 & $0.484-0.741$ & 1.46 & 84.2 \\
\hline & Kerman & 0.312 & $0.240-0.384$ & 4.63 & 95.4 \\
\hline \multirow{2}{*}{ Liver } & East Azerbaijan & 1.542 & $1.338-1.746$ & 1.21 & 97.4 \\
\hline & Kerman & 1.765 & $1.353-2.176$ & 0.30 & 81 \\
\hline \multirow{2}{*}{ Oral cavity } & East Azerbaijan & 1.476 & $1.195-1.756$ & 1.48 & 72.5 \\
\hline & Golestan & 6.496 & $5.561-7.432$ & 0.13 & 95.4 \\
\hline \multirow{2}{*}{ Pancreas } & East Azerbaijan & 0.695 & $0.502-0.887$ & 1.05 & 48 \\
\hline & Guilan & 0.462 & $0.365-0.559$ & 4.12 & 82.4 \\
\hline \multirow{2}{*}{ Small intestine } & East Azerbaijan & 1.067 & $0.825-1.309$ & 7.46 & 69.5 \\
\hline & Kerman & 0.898 & $0.605-1.191$ & 5.08 & 0 \\
\hline \multirow{2}{*}{ Stomach } & Golestan & 17.149 & $15.629-18.668$ & 0.28 & 99.5 \\
\hline & Kerman & 10.863 & $9.842-11.883$ & 0.63 & 98.6 \\
\hline
\end{tabular}

2. Azadeh S, Moghimi-Dehkordi B, Fatem SR, Pourhoseingholi MA, Ghiasi S, Zali MR. Colorectal cancer in Iran: an epidemiological study. Asian Pac J Cancer Prev. 2008;9(1):123-6. [PubMed: 18439090].

3. Kolahdoozan S, Sadjadi A, Radmard AR, Khademi H. Five common cancers in Iran. Arch Iran Med. 2010;13(2):143-6. [PubMed: 20187669].

4. Somi MH, Farhang S, Mirinezhad SK, Naghashi S, Seif-Farshad M, Golzari M. Cancer in East Azerbaijan, Iran: results of a populationbased cancer registry. Asian Pac J Cancer Prev. 2008;9(2):327-30. [PubMed: 18712985].

5. Semnani S, Sadjadi A, Fahimi S, Nouraie M, Naeimi M, Kabir J, et al. Declining incidence of esophageal cancer in the Turkmen Plain, eastern part of the Caspian Littoral of Iran: a retrospective cancer surveillance. Cancer Detect Prev. 2006;30(1):14-9. doi: 10.1016/j.cdp.2005.11.002. [PubMed: 16495018].

6. Ganji A, Malekzadeh F, Safavi M, Nasseri Moghaddam S, Nouraie M, Merat S. Digestive and Liver Disease Statistics in Iran. Middle East J Digest Dis. 2009;1(2):56-61.

7. Jackson-Thompson J, Ahmed F, German RR, Lai SM, Friedman C. Descriptive epidemiology of colorectal cancer in the United States, 1998-2001. Cancer. 2006;107(5 Suppl):1103-11. doi: 10.1002/cncr.22007. [PubMed: 16835911].

8. Rim SH, Seeff L, Ahmed F, King JB, Coughlin SS. Colorectal cancer incidence in the United States, 1999-2004 : an updated analysis of data from the National Program of Cancer Registries and the Surveillance, Epidemiology, and End Results Program. Cancer. 2009;115(9):1967-76. doi:10.1002/cncr.24216. [PubMed: 19235249].

9. Rozen P, Liphshitz I, Barchana M. Changing epidemiology of colorectal cancer makes screening sigmoidoscopy less useful for identifying carriers of colorectal neoplasms. Dig Dis Sci. 2012;57(8):2203-12. doi: 10.1007/s10620-012-2146-z. [PubMed: 22466099].

10. Mehrabani D, Tabei SZ, Heydari ST, Shamsina SJ, Shokrpour N, Amini M. Cancer Occurrence in Fars Province, Southern Iran. Iranian Red Crescent Med J. 2008;10(4):314-22.

11. Mirzaei M, Hosseini SA, Ghoncheh M, Soheilipour F, Soltani S, Soheilipour F, et al. Epidemiology and Trend of Head and Neck Cancers in Iran. Glob J Health Sci. 2016;8(1):189-93. doi: 10.5539/gjhs.v8n1p189. [PubMed: 26234980].

12. Mousavi SM, Gouya MM, Ramazani R, Davanlou M, Hajsadeghi
N, Seddighi Z. Cancer incidence and mortality in Iran. Ann Oncol. 2009;20(3):556-63. doi: 10.1093/annonc/mdn642. [PubMed: 19073863].

13. Safaee A, Fatemi SR, Ashtari S, Vahedi M, Moghimi- Dehkordi B, Zali R. Four years incidence rate of colorectal cancer in iran: A survey of national cancer registry data-implications for screening. Asian Pacific J Cancer Preven. 2012;13:2695-8.

14. Zeinalzadeh AH, Hosseini R, Abdullahi L. Survey of Epidemiology of Cancers in the Patients above 15 Years Old in East Azerbaijan Province, Iran 2013. J Ardabil Uni Med Sci. 2015;15:46-55.

15. Taefi A, Nouraie M, Ghorbani A, Fakheri H, Zahedi MJ, Semnani S. The incidence of pancreas and Billiary ducts cancers in Iran: A population based study [in Persian]. Govaresh. 2008;13(4):217-22.

16. Esmailnasab N, Moradi G, Zareaie M, Ghaderi A, Gheitasi B. Epidemiology and Incidence of cancers in people over 15 years of Kurdistan province. Scie J Kurdistan Uni Med Sci. 2005;11:18-25.

17. Ansari R, Mahdavinia M, Sadjadi A, Nouraie M, Kamangar F, Bishehsari $\mathrm{F}$, et al. Incidence and age distribution of colorectal cancer in Iran: results of a population-based cancer registry. Cancer Lett. 2006;240(1):143-7. doi: 10.1016/j.canlet.2005.09.004. [PubMed: 16288832].

18. Zahedi MJ, Darvishmoghadam S, Hayatbakhsh Abbasi M, Zeinalinejad $H$. The Incidence Rate of Gastrointestinal Tract Cancers in Kerman Province during 1996-2000. J Kerman Uni Med Sci. 2005;12:153-8.

19. Khabazkhub M, Mohagheghi SMA, Mousavi-Jarahi SAR, Javaherforoush A, Pedramfar M, Moradi A. The Incidence of Gastrointestinal Tract Cancers in Tehran Province during 1998-2001. Scie J Gorgan Uni Med Sci. 2009;11(4):44-50.

20. Yousef F, Cardwell C, Cantwell MM, Galway K, Johnston BT, Murray $\mathrm{L}$. The incidence of esophageal cancer and high-grade dysplasia in Barrett's esophagus: a systematic review and meta-analysis. Am J Epidemiol. 2008;168(3):237-49. doi: 10.1093/aje/kwn121. [PubMed: 18550563].

21. Yazdani Charati J, Zare S, Ghorbanpour E, Shabankhani B. Demographic and Geographical Pattern of Mortality Rate from Stomach Cancer and Related Factors in Mazandaran Province From 2001 to 2005. J Mazandaran Uni Med Sci. 2009;20(79):2-7.

22. Nourozinia F, Rasmi Y, Otarod M, Golizadeh M, Khadem-Ansari MH 
Epidemiology And Histopathology Of Gastric Cancer In Urmia. Urmia Med J. 2013;24(3):170-5.

23. Mobasheri M, Ahmadi A. Incidence Patterns and Spatial Analysis of the Most Common Cancers in Southeastern Iran Using Geographic Information System (GIS). Academic J Cancer Res. 2014;7(2):141-5. doi: 10.5829/idosi.ajcr.2014.7.2.83269.

24. Kamangar F, Malekzadeh R, Dawsey SM, Saidi F. Esophageal cancer in
Northeastern Iran: a review. Arch Iran Med. 2007;10(1):70-82. [PubMed: 17198458].

25. Islami F, Pourshams A, Nasrollahzadeh D, Kamangar F, Fahimi S, Shakeri R, et al. Tea drinking habits and oesophageal cancer in a high risk area in northern Iran: population based case-control study. BMJ. 2009;338:929. doi:10.1136/bmj.b929. [PubMed: 19325180]. 